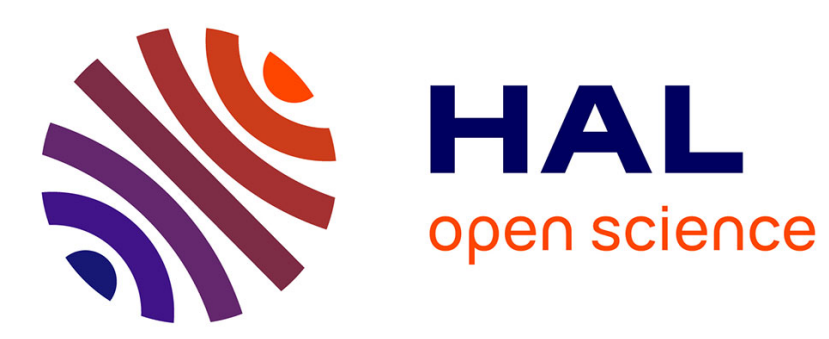

\title{
Resistivity saturation effect in thin V-Al alloy films
}

B. Stolecki

\section{- To cite this version:}

B. Stolecki. Resistivity saturation effect in thin V-Al alloy films. Journal de Physique, 1989, 50 (6), pp.675-683. 10.1051/jphys:01989005006067500 . jpa-00210945

\section{HAL Id: jpa-00210945 https://hal.science/jpa-00210945}

Submitted on 1 Jan 1989

HAL is a multi-disciplinary open access archive for the deposit and dissemination of scientific research documents, whether they are published or not. The documents may come from teaching and research institutions in France or abroad, or from public or private research centers.
L'archive ouverte pluridisciplinaire HAL, est destinée au dépôt et à la diffusion de documents scientifiques de niveau recherche, publiés ou non, émanant des établissements d'enseignement et de recherche français ou étrangers, des laboratoires publics ou privés. 
Classification

Physics Abstracts

$72.10-73.60$

\title{
Resistivity saturation effect in thin V-Al alloy films
}

\author{
B. Stolecki
}

Institute of Physics, Technical University of Wroclaw, Wybrzeze Wyspianskiego 27, 50-370 Wroclaw, Poland

\begin{abstract}
Résumé. - La résistivité de films minces d'alliage $\mathrm{V}$-Al de diverses épaisseurs et compositions a été étudiée en fonction de la température. Les films ont été évaporés sous vide $\left(10^{-5} \mathrm{~Pa}\right)$ à l'aide d'un canon à électrons sur des substrats de quartz maintenus à température ambiante. Les mesures de résistivité ont été effectuées in situ entre 300 et $380 \mathrm{~K}$ dans un vide de $10^{-8}-10^{-6} \mathrm{~Pa}$. Il a été observé une dépendance anormale de la résistivité en température sous forme d'une saturation. Cet effet a été analysé à l'aide d'un modèle de résistances en dérivation.

Abstract. - The resistivity of the V-Al alloy films of various thicknesses and compositions was studied as a function of temperature. The films were evaporated using an electron gun in a vacuum of $10^{-5} \mathrm{~Pa}$ onto quartz substrates held at room temperature. The resistivity measurements were carried out in situ in vacuum of $10^{-8}-10^{-6} \mathrm{~Pa}$ in the temperature range $300-830 \mathrm{~K}$. It was found that the resistivity dependence on temperature was anomalous, i.e., the resistivity saturation effect occurred. An analysis of this effect was performed on the basis of the shunt resistance model.
\end{abstract}

\section{Introduction.}

The electrical properties of metal alloys frequently differ significantly from the properties of typical metals. The property differences are particularly evident for alloys with resistivities of the order of $150 \mu \Omega \mathrm{cm}$ or higher. Most of the high resistivity conductors are transition metal alloys. The resistivity $(\rho)$ dependence on temperature $(T)$ for these conductors does not correspond to the Bloch-Boltzmann theory. Mooij [1] observed that they are subject to certain rules. The temperature coefficient of resistivity (TCR) $\alpha=(1 / \rho)(\mathrm{d} \rho / \mathrm{d} T)$ of highly resistive conductors at room temperature is much lower than that expected from the BlochBoltzmann theory. Moreover, the TCR becomes negative for conductors which have a resistivity greater than $150 \mu \Omega \mathrm{cm}$ and is positive for the others.

In the case of alloys with a high concentration of defects the mean free path (MFP) $\lambda$ of electrons approaches the inter atomic spacing $a$. According to the Ioffe-Regel criterion [2] the MFP values cannot decrease below $a$, so that the Bloch-Boltzmann theory based on the nearly-free-electron (NFE) model is no longer valid for such materials. On the other hand the fact that the MFP may attain its minimum value in the case of highly resistive conductors was used in the works by Mooij [1] and then by Fisk and Webb [3] for the explanation of anomalies observed in the temperature dependence of resistivity of these conductors. Fisk 
and Webb described for $\mathrm{Nb}_{3} \mathrm{Sb}$ and $\mathrm{Nb}_{3} \mathrm{Sn}$ a resistivity saturation, i.e., an effect that the alloy resistivity increases with increasing temperature to a certain value $\rho^{*}=150 \mu \Omega \mathrm{cm}$. The function $\rho(T)$ for highly resistive conductors can be described in a wide temperature range within the framework of the shunt resistance model introduced by Wiesmann et al. [4]. In this model the conductor resistivity depends on the ideal resistivity $\rho_{\mathrm{i}}(T)$ derived from the BlochBoltzmann theory and the saturated resistivity $\rho^{*}$

$$
\frac{1}{\rho(T)}=\frac{1}{\rho_{\mathrm{i}}(T)}+\frac{1}{\rho^{*}}
$$

This model was substantiated by Gurvitch [5] who also showed that the saturated resistivity $\rho *$ depends on the electron concentration $n$ as follows

$$
\rho^{*}=\frac{1.29 \times 10^{10}}{n^{2 / 3} a} \mu \Omega \mathrm{cm} .
$$

By using compiled experimental data Tsuei [6] demonstrated that the saturated resistivity can have values ranging from 30 to $400 \mu \Omega \mathrm{cm}$. He also analysed the dependence of the TCR on the resistivity and showed that its saturated value depends on the Fermi level and degree of disorder of the studied metal. Therefore, according to Tsuei, no fundamental significance should be attached to the resistivity value of $150 \mu \Omega \mathrm{cm}$.

It should be emphasized that the shunt resistance model is a rather simplified approach to the problem of anomalies in electrical properties of highly resistive conductors. However, this problem has not yet been described theoretically in a satisfactory manner (i.e., with taking into account its entire complexity). Consequently, the experimental data for conductors which exhibit the resistivity saturation effect are frequently interpreted by the use of the shunt resistance model $[7,8]$. In this work the above mentioned model is applied to analyse the resistivity behaviour of $\mathrm{V}-\mathrm{Al}$ alloy films.

Effective investigations of electrical conductance mechanisms in metal alloys generally require, a large solubility of one of the alloy components in the lattice of the other one. From phase equilibria of the $\mathrm{V}-\mathrm{Al}$ alloy [9] it is known that the solubility of aluminium in vanadium is large and attains at $800 \mathrm{~K}$ a value as high as 40.5 at \%. The aluminium atoms dissolved in the vanadium lattice are, along with the other existing lattice defects, scattering centres for conduction electrons. Thus, high aluminium concentrations in vanadium lead to the MFP decrease to values close to the interatomic spacing. According to the previous statements the electrical conduction behaviour of such a system cannot be interpreted on the basis of the NFE theory. Therefore, studies of $\mathrm{V}$-Al alloy films offer a good opportunity for the analysis of the electrical properties of highly resistive conductors. They also create the conditions required for the resistivity saturation effect to arise.

\section{Experimental details.}

Thin $\mathrm{V}-\mathrm{Al}$ alloy films were deposited onto quartz substrates held at room temperature and in vacuum of $10^{-5} \mathrm{~Pa}$ in a Riber UNI 5P system. They were obtained by means of an electron gun with a controlled beam. The electron gun system possessed two seats. Both components of the alloy ( $5 \mathrm{~N}$ aluminium and $99.7 \%$ vanadium), placed in separate seats, were evaporated simultaneously. The schematic diagram of the substrate with the films, electrodes and a thermocouple is presented in figure 1. Each evaporation process yielded five films (on a single substrate) of various thicknesses depending on the deposition time, which was controlled by screening part of the substrate with a shutter. 


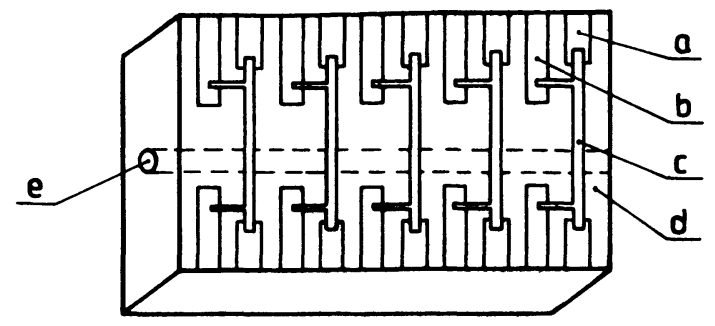

Fig. 1. - The substrate with the evaporated electrodes and films : a) current electrodes; b) voltage electrodes ; c) films ; d) quartz substrate ; e) hole for a thermocouple.

Vanadium was used for the electrode deposition to prevent chemical reactions at the interface between the film and the electrodes during the annealing. Such reactions occurred at higher temperatures when the other metals were used for the electrodes, and as a consequence, the electrical contacts suffered destruction.

During the measuring procedure the substrate temperature was changed in a range from 300 to $830 \mathrm{~K}$. It was monitored using an iron-constantan thermocouple. The film thickness was determined by means of the Tolansky method [10]. The film resistance was measured in a vacuum of $10^{-6}-10^{-8} \mathrm{~Pa}$. The measurements were carried out for each temperature after a $20 \mathrm{~min}$ isothermal annealing step. The atomic fractional composition was determined using the X-ray microprobe method.

\section{Experimental results.}

The results of the resistivity measurements for the most representative $\mathrm{V}$-Al alloy films with various atomic compositions are presented in figures 2 to 5 . These data illustrate the resistivity dependence on temperature related to the composition changes.

Film a shown in figure 2 possessed in the as-prepared state the resistivity marked as point A. The experimental points on curve $A B$ denote the film resistivity after subsequent

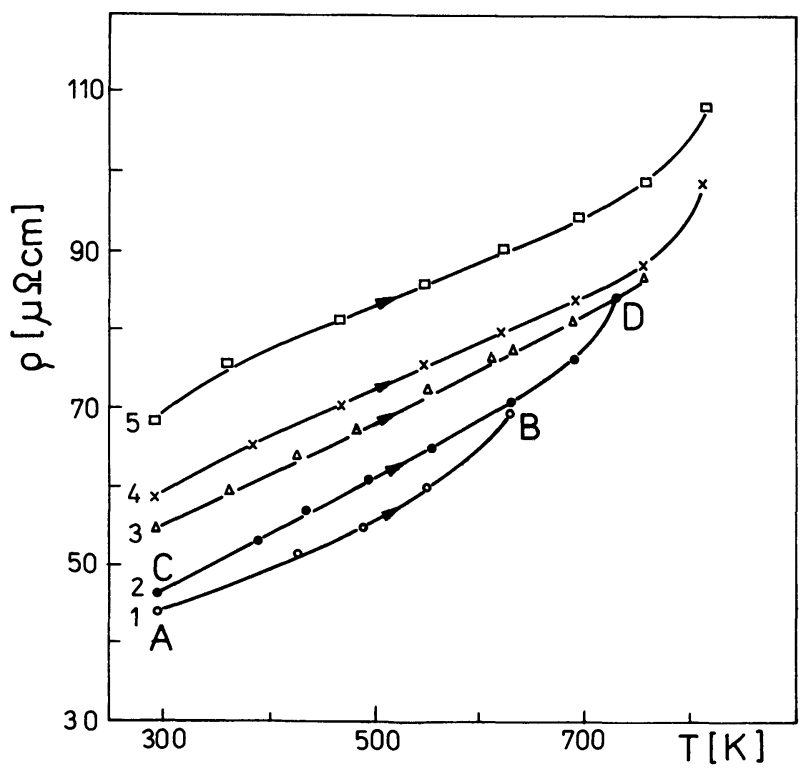

Fig. 2. - Temperature dependence of the resistivity $\rho$ of film a $\left(\mathrm{V}_{0.99} \mathrm{Al}_{0.01}, d=44.5 \pm 0.5 \mathrm{~nm}\right)$. 
processes of isothermal annealing. Then, the films were cooled to room temperature (the resistivity marked as point $C$ ). The points on curve $C D$ represent the next series (2) of subsequent annealing processes. The different annealing series are marked by different symbols and labelled from 1 to 5. Each annealing series started at room temperature and, with respect to the previous run, finished at a higher temperature.

Figures 3 to 5 present the resistivity dependence on temperature for $\mathrm{V}$-Al alloy films with atomic compositions 5 and 7 at $\% \mathrm{Al}$. The films are denoted b, c, d. The particular annealing series are marked, similarly to the notation in figure 2 , by different symbols and labelled with appropriate numbers. Several series of annealing processes conducted on the films b, c and d are presented in figures 3,4 and 5 , respectively.

\section{Discussion.}

The V-Al alloy films show a significant gas absorption. Oxygen is the particularly active residual gas which easily forms many compounds with vanadium (VO, $\mathrm{VO}_{2}, \mathrm{~V}_{2} \mathrm{O}_{3}$,

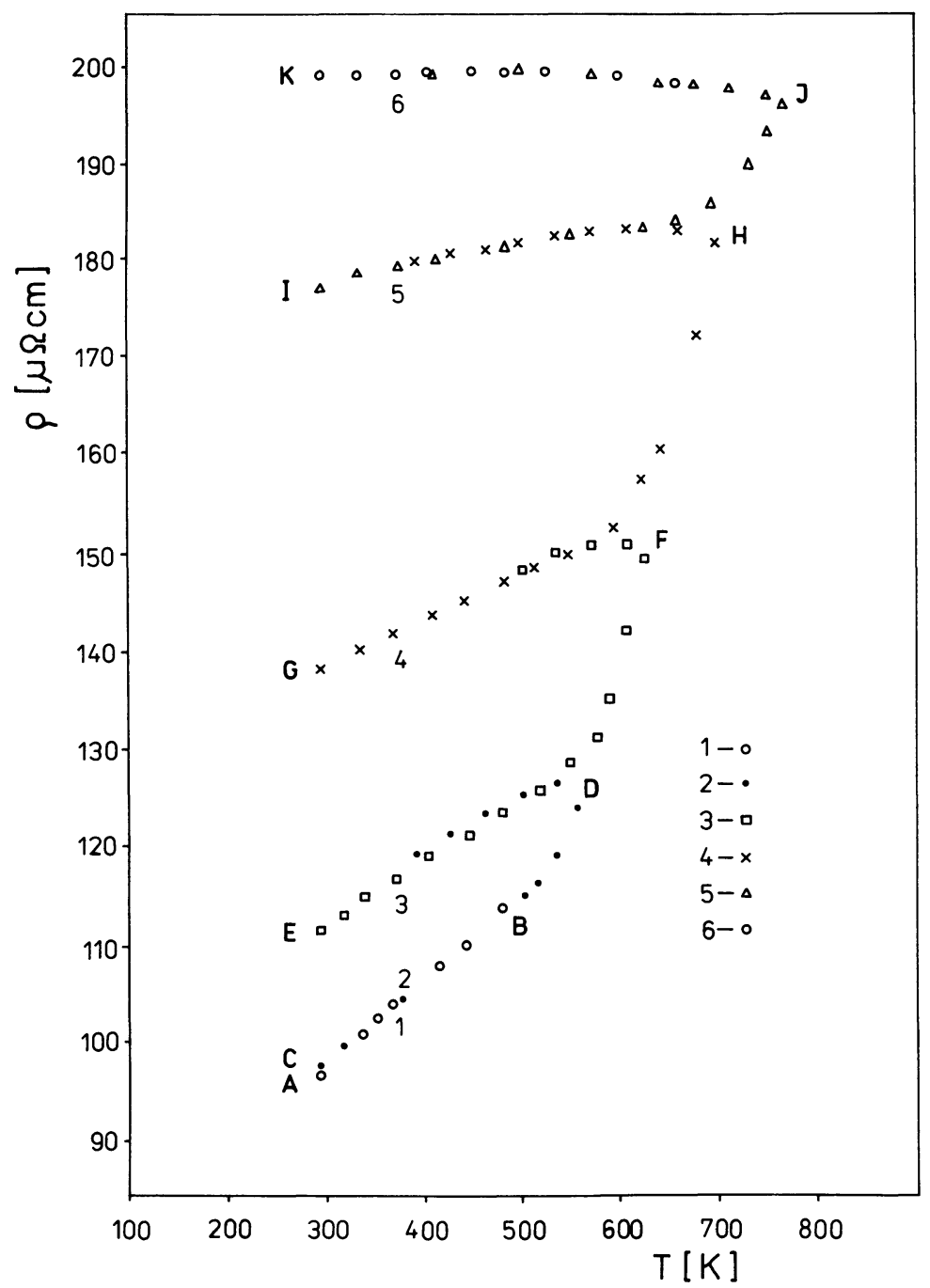

Fig. 3. - Temperature dependence of the resistivity $\rho$ of film $\mathrm{b}\left(\mathrm{V}_{0.95} \mathrm{Al}_{0.05}, d=39.5 \pm 0.5 \mathrm{~nm}\right)$. 


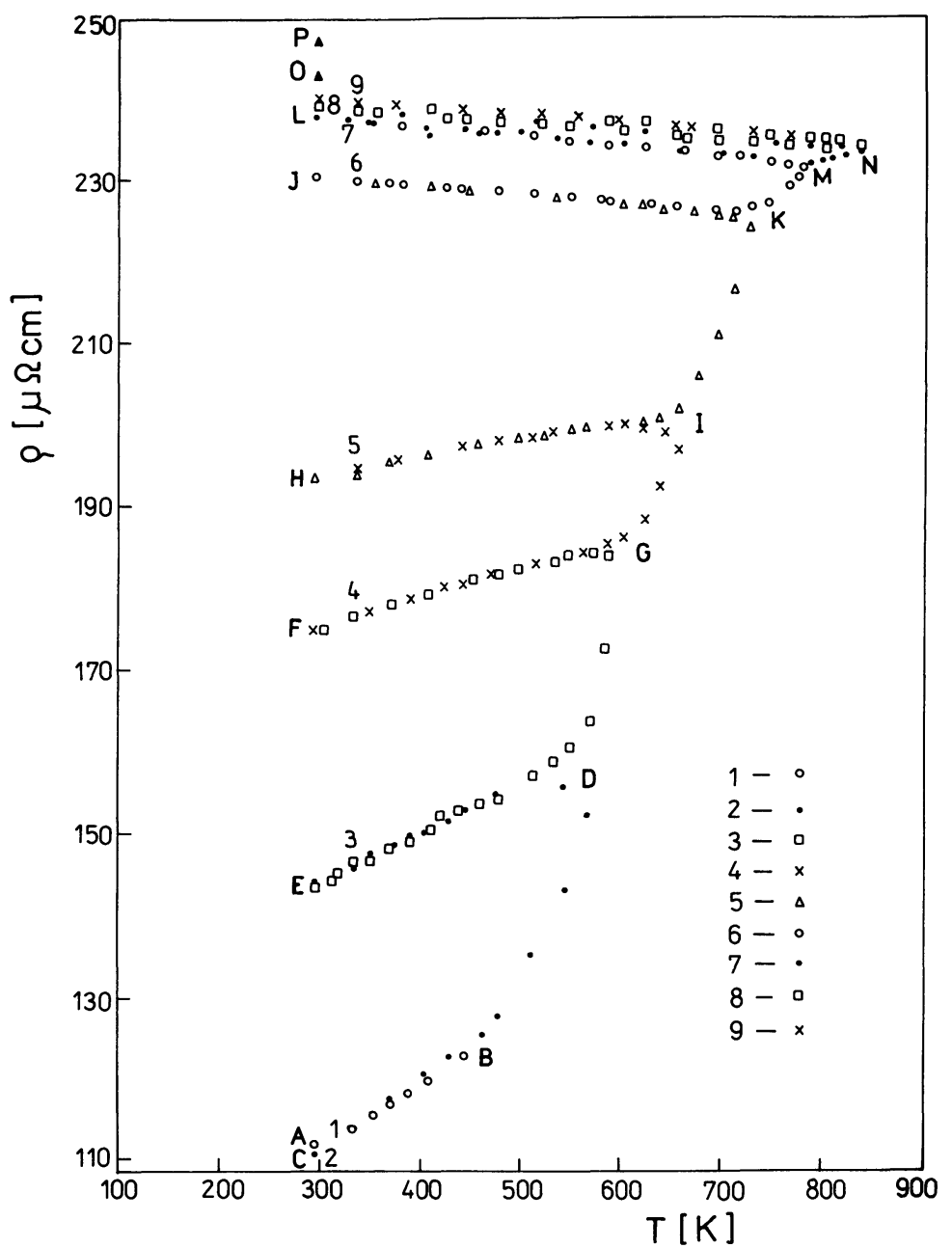

Fig. 4. - Temperature dependence of the resistivity $\rho$ of film $\mathrm{c}\left(\mathrm{V}_{0.93} \mathrm{Al}_{0.07}, d=20.5 \pm 0.5 \mathrm{~nm}\right)$.

$\mathrm{V}_{2} \mathrm{O}_{5}$ and so on) and the well-known $\mathrm{Al}_{2} \mathrm{O}_{3}$. The temperature increase activates the process of residual gas diffusion inside films, and consequently, activates the process of oxygen bonding. Therefore, to eliminate the residual gas influence the ultrahigh vacuum is required for studies of electrical properties of the alloy films at high temperatures. It also explains that only a few experiments on $\mathrm{V}$-Al films have been published. Mooij [1] studied the conductivity of V-Al alloys (produced by sputtering) with compositions of $20-40$ at $\% \mathrm{Al}$ in a temperature range from 80 to $400 \mathrm{~K}$. He obtained a negative TCR over the whole temperature range. In this work the $\mathrm{V}-\mathrm{Al}$ films were evaporated in the high vacuum and investigated in situ. Consequently, the analysed films were qualitatively different from those described in the work by Mooij.

Figure 2 presents the data for the film a of $\mathrm{V}_{0.99} \mathrm{Al}_{0.01}$, which is a low resistivity conductor owing to its low aluminium content. Before annealing, the film resistivity $(44.1 \mu \Omega \mathrm{cm})$ was close to that of pure vanadium films [11] and about twice the resistivity of bulk vanadium $(19.9 \mu \Omega \mathrm{cm}$ at $295 \mathrm{~K})[12,13]$. The value $\mathrm{d} \rho / \mathrm{d} T=0.069 \mu \Omega \mathrm{cm} \mathrm{K}^{-1}$ for the film a taken (curve CB) is slightly smaller than the value $\mathrm{d} \rho / \mathrm{d} T=0.074 \mu \Omega \mathrm{cm} \mathrm{K}{ }^{-1}$ for the bulk alloy. 


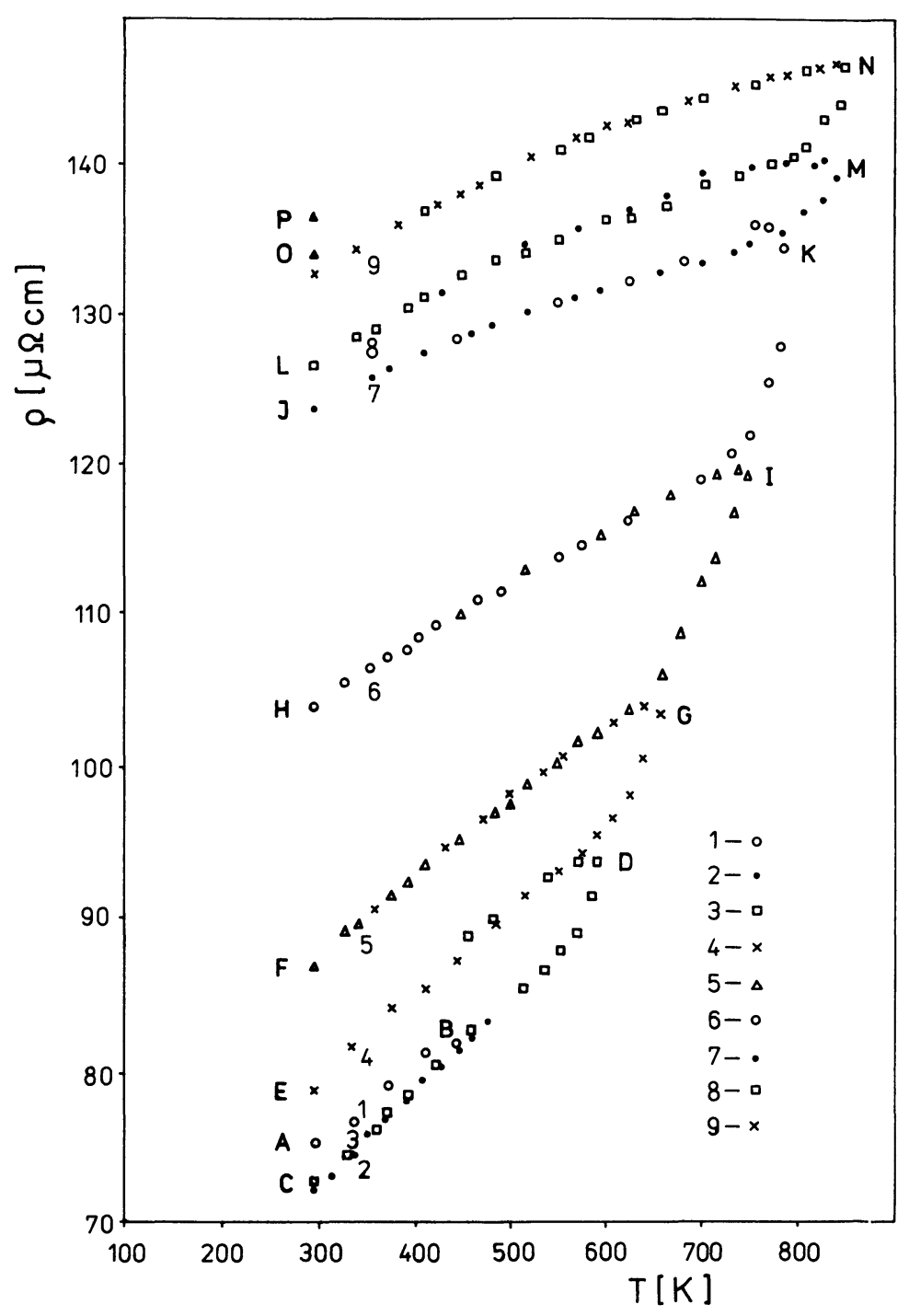

Fig. 5. - Temperature dependence of the resistivity $\rho$ of film $\mathrm{d}\left(\mathrm{V}_{0.93} \mathrm{Al}_{0.07}, d=63.5 \pm 0.5 \mathrm{~nm}\right)$.

Subsequent annealing series (1-5) up to progressively higher temperatures caused neither a significant decrease in the value of $\mathrm{d} \rho / \mathrm{d} T$ nor a rapid increase in the resistivity (from $44.1 \mu \Omega \mathrm{cm}$ to $69.2 \mu \Omega \mathrm{cm}$ ). The increase in the resistivity which occurred during the final stage of each annealing series was irreversible. It is obvious that the main reason of the considered changes is the gas absorption. This was particularly true at higher temperatures when the vacuum deteriorated to $10^{-6} \mathrm{~Pa}$. The resistivity changes occurring at the early stages of each annealing series were reversible and linear, in particular in series 2 and 3 . This is a characteristic feature of low resistance conductors with a long MFP of electrons. Thin films of such conductors exhibit an electrical size effect. Studies of this effect in films of pure vanadium were reported in the work by Borodziuk-Kulpa et al. [11] and according to these results the MFP was $1.2 \times 10^{-9} \mathrm{~m}$ at room temperature. 
The resistivity dependence on temperature for the film $b$ of $\mathrm{V}_{0.95} \mathrm{Al}_{0.05}$ alloy is presented in figure 3. The film exhibited the resistivity saturation effect, especially in the final series of the isothermal annealing processes. Due to the increased aluminium content (5\%), the sample became a highly resistive conductor. The film resistivity in the as-prepared state (marked as point A) was $97.2 \mu \Omega \mathrm{cm}$. The resistivity changes during the first annealing series are reversible (circles in Fig. 3). Point $\mathrm{C}$ indicates the resistivity value of the film cooled to room temperature. Next annealing series (2-6) which are marked with different symbols led to the irreversible resistivity increase and the decrease of $\mathrm{d} \rho / \mathrm{d} T$ value. The film attained the negative TCR value after the final annealing series (6). The obtained resistivity dependences on temperature, illustrated as curves ED, GF and IH for reversible changes, became more non-linear with increasing annealing temperature. It is apparent that, after the last two annealing series $(5,6)$, the film possessed the typical properties of highly resistive conductors. It exhibited the resistivity saturation effect and satisfied Mooij's law.

Figure 4 shows the results obtained for the film $c$ of $\mathrm{V}_{0.93} \mathrm{Al}_{0.07}$ alloy. They are similar to those found for film $b$. The considered sample was also a highly resistive conductor. Subsequent annealing series (1-9) up to progressively higher temperatures caused the increase of the film resistivity and the decrease of TCR down to negative values. Film c also exhibited the resistivity saturation effect and was subject to Mooij's rule. It is worth noting that the influence of gas absorption on the resistivity at room temperature is proved by points $\mathrm{O}$ and $\mathrm{P}$ where these points present the film resistivities at the pressures $10^{-8} \mathrm{~Pa}$ and $10^{5} \mathrm{~Pa}$ (atmospheric pressure), respectively.

The resistivity as a function of temperature for the film $\mathrm{d}$ of $\mathrm{V}_{0.93} \mathrm{Al}_{0.07}$ alloy, i.e., with the same composition as in the case of film c but of greater thickness, is illustrated in figure 5 . The general resistivity behaviour is analogous to that observed in figures 3 and 4 . The resistivity dependences on temperature also became more non-linear with increasing annealing temperature. Curves LM and ON show the resistivity saturation effect which is in agreement with the shunt resistance model proposed by Wiesmann [5]. The resistivity ${ }^{\top}(\rho)$ as a function of temperature for these two curves can be described by equation (1) derived within Wiesmann's model. The expression for $\rho_{1}(T)$ obtained from the NFE model is linear in character at higher temperatures and may be rewritten in the form

$$
\rho_{1}(T)=\rho_{0}+\beta T,
$$

where $\rho_{0}$ is the approximate residual resistivity and $\beta$ is a constant. From equations (1) and (3) the simple expression which is linear with respect to temperature may be derived

$$
\left\{\frac{1}{\rho(T)}-\frac{1}{\rho^{*}}\right\}^{-1}=\rho_{0}+\beta T .
$$

The above equation constitutes an important criterion allowing us to ascertain whether a conductor which shows a given temperature dependence of its resistivity exhibits the resistivity saturation effect. In other words it renders it possible to find the conductor saturated resistivity $\rho^{*}$, if any, for which the dependence given by equation (4) is linear. The $\rho$ * value calculated for curves $\mathrm{LM}$ and $\mathrm{ON}$ is equal to $160 \mu \Omega \mathrm{cm}$.

The graphs obtained from equation (4) for this saturated resistivity value are, in fact, linear. This is illustrated in figure 6 . The other values of $\rho^{*}$ found by means of this method for the films b and c are $192 \mu \Omega \mathrm{cm}$ and $223 \mu \Omega \mathrm{cm}$, respectively. The fact that the saturated resistivity values were different for the films $b, c$ and $d$ may be explained on the basis of the studies by Gurvitch [5] and Tsuei [6]. They showed that the saturated resistivity $\rho *$ can vary from 30 to $400 \mu \Omega \mathrm{cm}$ and depends very much on the individual material and its disorder. In the case of the films $b, c$ and $d$ the particular sample disorders were obviously 


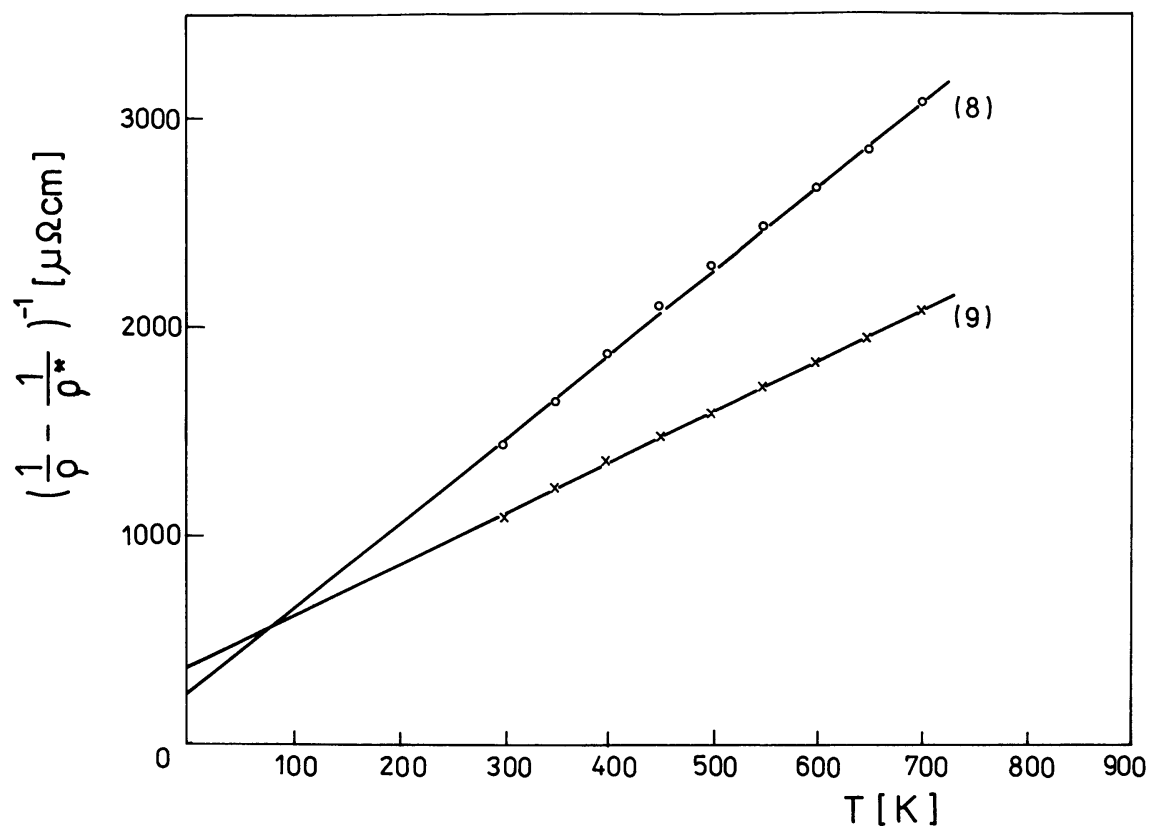

Fig. 6. - Plots of $\left\{\frac{1}{\rho}-\frac{1}{\rho^{*}}\right\}^{-1}$ versus temperature for film $\mathrm{d}$ after the eighth and ninth series of annealing steps.

different because of the different annealing temperature. Moreover, one may expect that aluminium dissolved in the vanadium lattice as well as gases absorbed in alloy films can cause the decrease of the concentration of conduction electrons in the samples. The gas absorption is especially dependent on the temperature, so it seems to be substantiated that the electron concentrations were different for films b, c and d. According to equation (2) it also means that the values of $\rho^{*}$ were different for these films.

It should also be emphasized that dissolved aluminium and absorbed gases introduced a significant defect concentration in the studied films. These defects reduced the MFP value from $1.2 \times 10^{-9} \mathrm{~m}$ for pure vanadium films at room temperature [11] to values close to the interatomic distance for alloy films. The above mentioned MFP shortening seems to be the most reasonable explanation for the occurrence of an anomaly in the electrical transport properties of thin $\mathrm{V}-\mathrm{Al}$ alloy films. It is in agreement with various papers $[1,2,5]$ on the mechanisms of the resistivity saturation effect.

Assent to the MFP shortening as the reason for the resistivity saturation effect can be convincingly substantiated on the basis of the free electron model for metals. In this model the electron MFP has the form

$$
\lambda=\frac{6 \pi^{2} h}{e^{2} \rho S},
$$

where $h$ is Planck's constant, $e$ is the electron charge, $\rho$ is the metal resistivity and $S$ is the area of the Fermi surface. Assuming for simplicity that $\mathrm{V}$-Al alloy films satisfy this simple model, the MFP of conduction electrons can be determined for the saturated resistivity. Using the value of $\rho^{\lambda}=3.5 \times 10^{-10} \mu \Omega \mathrm{m}^{2}$ for pure vanadium given by Radebaugh and Keesom [14] the MFP value $\lambda=0.18 \mathrm{~nm}$ can be calculated for a saturation resistivity $\rho^{*}=192 \mu \Omega \mathrm{cm}$ 
(film b). The vanadium lattice constant is $0.303 \mathrm{~nm}$ and the distance between the nearest neighbours in the vanadium lattice is $0.263 \mathrm{~nm}$. Even if one takes into account the fact that the free electron model is, in this case, only a rough approximation, one can notice that the electron MFP is almost equal to the interatomic distances. Consequently, the previous statement that the cause of resistivity saturation is a reduction of the MFP to the interatomic distances seems to be sufficiently confirmed.

\section{Summary.}

The following conclusions can be drawn on the basis of the results of the studies performed on thin V-Al alloy films :

a) The resistivity of alloy films which contain aluminium up to a few per cent is, in the asprepared state, proportional to the aluminium concentration in the samples.

b) The $\mathrm{V}-\mathrm{Al}$ alloy films with aluminium contents of a few per cent or more become, after annealing, highly resistive conductors.

c) They also exhibit the resistivity saturation effect as predicted by Wiesmann's model [4].

d) The films with resistivities higher than the saturation resistivity exhibit negative TCR.

e) The resistivity saturation effect results from a reduction of the electron mean free path to values close to the interatomic distances.

\section{Acknowledgments.}

Special thanks are expressed to Professor C. Wesolowska for scientific supervision and inspiration.

This work was sponsored by the Polish Ministry of National Education under Contract CPBP 01.06.

\section{References}

[1] Mools J. M., Phys. Status Solidi 17 (1973) 521.

[2] Ioffe A. F. and Regel A. R., Prog. Semicond. 4 (1960) 237.

[3] Fisk Z. and Webb G. W., Phys. Rev. Lett. 36 (1976) 1084.

[4] Wiesmann H., Gurvitch M., Lutz H. and Ghosh, A., Phys. Rev. Lett. 38 (1977) 782.

[5] Gurvitch M., Phys. Rev. B 24 (1981) 7404.

[6] Tsuei C. C., Phys. Rev. Lett. 57 (1986) 1943.

[7] Savvides N., Hurd G. M. and McAllister S. P., Solid State Commun. 41 (1982) 735.

[8] Martin R. A. and Corruccini L. R., J. Low Temp. Phys. 55 (1984) 527.

[9] HANSEN M., Constitution of Binary Alloys, McGraw-Hill Book Company, Inc., New YorkToronto-London, 1958.

[10] Tolansky S., Multiple Beam Interferometry of Surfaces and Films (Oxford University Press, Fair Lawn, NY) 1948.

[11] Borodziuk-Kulpa A., Stolecki B. and Wesolowska C., J. Mater. Sci. 16 (1981) 1661.

[12] Meaden G. T., Electrical Resistance of Metals, Heywood (London) 1966.

[13] Peletsky W. E., Teplofiz. Wys. Temp. 16 (1978) 72.

[14] Radebaugh R. and Keesom H., Phys. Rev. 149 (1966) 217. 